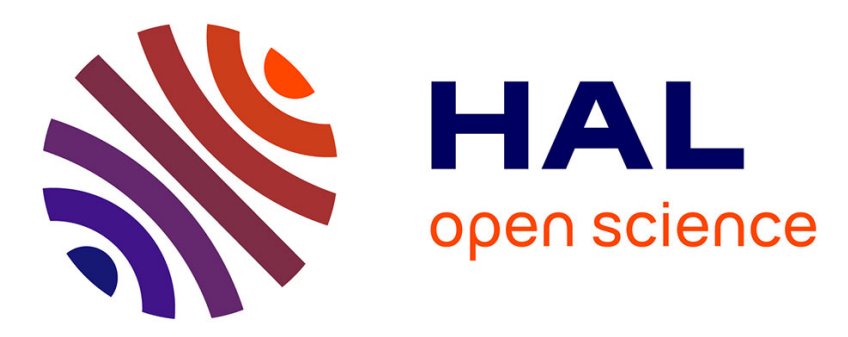

\title{
Preparing the astrocyte perivascular endfeet transcriptome to investigate astrocyte molecular regulations at the brain vascular interface
} Anne-Cécile Boulay, Noémie Mazaré, Bruno Saubamea, Martine Cohen-Salmon

\section{To cite this version:}

Anne-Cécile Boulay, Noémie Mazaré, Bruno Saubamea, Martine Cohen-Salmon. Preparing the astrocyte perivascular endfeet transcriptome to investigate astrocyte molecular regulations at the brain vascular interface. Methods Mol Biol, pp.105-116, 2019, 10.1007/978-1-4939-9068-9_8 . hal-02330671

\section{HAL Id: hal-02330671 \\ https://hal.science/hal-02330671}

Submitted on 24 Oct 2019

HAL is a multi-disciplinary open access archive for the deposit and dissemination of scientific research documents, whether they are published or not. The documents may come from teaching and research institutions in France or abroad, or from public or private research centers.
L'archive ouverte pluridisciplinaire $\mathbf{H A L}$, est destinée au dépôt et à la diffusion de documents scientifiques de niveau recherche, publiés ou non, émanant des établissements d'enseignement et de recherche français ou étrangers, des laboratoires publics ou privés. 


\section{Preparing the astrocyte perivascular endfeet transcriptome to investigate astrocyte molecular regulations at the brain vascular interface}

Anne-Cécile Boulay ${ }^{1}$, Noémie Mazaré1, Bruno Saubaméa², Martine Cohen-Salmon ${ }^{1}$

${ }^{1}$ Collège de France, Center for Interdisciplinary Research in Biology (CIRB)/ Centre National de la Recherche Scientifique CNRS, Unité Mixte de Recherche 7241/ Institut National de la Santé et de la Recherche Médicale INSERM, U1050 / 75231 Paris Cedex 05, France ; Paris Science Lettre Research University, 75005 Paris, France.

${ }^{2}$ Institut National de la Santé et de la Recherche Médicale INSERM U1144, Paris, F-75006, France ; Université Paris Descartes, UMR-S 1144, Paris, F-75006, France ; Université Paris Diderot, UMR-S 1144, Paris, F-75013, France

*Correspondence: martine.cohen-salmon@college-de-france.fr Authors declare no conflict of interest.

Acknowledgments: This work has received support under the program "Investissements d'Avenir" launched by the French Government and implemented by the ANR, with the references: ANR-10-LABX-54 MEMO LIFE, ANR-11-IDEX-0001-02 PSL* Research University and by Fondation pour la recherche médicale (AJE20171039094).

\section{Running head}

Preparing the endfeetome 


\begin{abstract}
Astrocytes send out long processes that are terminated by endfeet at the vascular surface and regulate vascular functions in particular through the expression of a specific molecular repertoire in perivascular endfeet. We recently proposed that local translation might sustain this structural and functional polarization. More specifically we showed that a subset of mRNAs is distributed in astrocyte endfeet and characterized this transcriptome. We also identified among these endfeet RNAs, the ones bound to ribosomes, the polysomal astrocyte endfeet mRNAs, which we called the endfeetome. Here, we describe experimental strategies to identify mRNAs and polysomes in astrocyte perivascular endfeet, which are based on the combination of gliovascular unit purification and astrocyte specific translating ribosome affinity purification.
\end{abstract}

\title{
Keywords
}

Astrocyte; Endfeet; Brain vessels; Gliovascular unit; Transcriptome; Translating ribosome affinity purification (TRAP) 


\section{Introduction}

Translation in cell areas distal from the soma is a well-recognized paradigm of morphologically complex cells, allowing local, rapid and efficient regulations, which are independent from somatic protein synthesis. In this process, mRNAs compacted into granules with specific RNA binding proteins escape translation in the cell soma and are sent to specific sites to be locally translated. In the brain, this operating mode has been well characterized in neurons which axons and dentritic arborization can cover very long distances [1]. It has also been shown to be critical for axon formation or in the fine regulation of neurotransmission [2]. Interestingly, three independent studies recently demonstrated that local translation also occurs in other neural cells such as astrocytes, which are the most numerous glial cells in the brain [35]. As neurons, astrocytes display a complex morphology with multiple processes covering large cellular domains and contacting synapses and brain vessels. At these specific interfaces, astrocytes influence synapse formation and function as well as cerebrovascular properties. Remarkably, blood vessels in the brain are almost entirely sheathed by astrocyte processes, also called endfeet, where astrocytes display a specific molecular repertoire involved in the regulation of critical vascular properties such as blood-brain barrier integrity, immune surveillance mechanisms, blood flow regulation and homeostasis [6]. Although the role of astrocytes in the regulation of cerebrovascular functions is well recognized, the way they fulfill it is however far from being understood.

In a recent study, we demonstrated that local translation occurs in astrocyte perivascular endfeet [4]. Moreover, we showed that these subcellular and distal astroglial compartments are equipped with the necessary organelles for translation, protein maturation and secretion, i.e. ribosomes, rough and smooth endoplasmic reticulum and the Golgi apparatus. We identified a pool of mRNAs present in astrocyte perivascular endfeet (the astrocyte endfeet transcriptome) and among them, those linked to ribosomes (polysomal mRNAs). Finally, we compared the 
distribution of polysomal mRNAs in whole astrocytes and in perivascular endfeet. The list of most abundant polysomal mRNAs present in astrocyte perivascular endfeet was named the endfeetome. It comprises mRNAs encoding well-known astrocyte endfeet markers such as Aqp4 (Aquaporin 4) and Cx43 (Connexin 43) but also previously unknown markers of the gliovascular unit. Starting from the idea that local translation is a key biological process to regulate astrocyte functions at the vascular interface, the endfeetome might therefore represent a list of potentially important astroglial proteins involved in the regulation of cerebrovascular functions.

Here, we describe the experimental strategy to purify and characterize on one hand mRNAs distributed in astrocyte perivascular endfeet, and on the other hand the endfeetome, the pool of polysomal mRNAs in astrocyte endfeet. The identification of these mRNAs distributed in astrocyte endfeet is based on the comparison of mRNAs extracted from purified microvessels units retaining or not astrocyte endfeet $[7,4]$. The identification of polysomal endfeet mRNAs is based on the combined purification of the gliovascular unit with an astrocyte specific ribosome affinity purification protocol (TRAP) [8]. 


\section{Materials}

The ultimate goal of this protocol is to purify intact mRNAs from astrocyte endfeet. Therefore, all manipulations require an RNase-free environment: use aerosol-resistant pipette tips and RNase-free reagents and DEPC-treated water, decontaminate benches with RnaseZap (Thermofisher, ref. AM9780), change gloves often. All solutions should be prepared the day before experiment, and kept at $4^{\circ} \mathrm{C}$ and always keep samples on ice. In all buffers, add $1 \mu \mathrm{L} / \mathrm{mL}$ RNAsin just before use to inhibit RNases. To extract polysomes, add $100 \mu \mathrm{g} / \mathrm{mL}$ Cycloheximide (CHX) to all solutions to stabilize mRNA-ribosome complexes. Use EDTAfree reagents since EDTA dissociates polysomes.

\subsection{Purification of mRNAs from the gliovascular unit}

1. DEPC-treated (RNAse free) water

2. RNAsin

3. Cycloheximide (CHX): prepare $100 \mathrm{mg} / \mathrm{mL}$ (1000x) stock solution in Methanol the day of the experiment

4. Buffer 1 (B1): 10 mM HEPES in HBSS (calcium, magnesium, no phenol red).

5. Buffer 2 (B2): 18\% Dextran (from Leuconostoc spp. Mr 70,000 in B1.

6. Buffer 3 (B3): 1\% Bovine serum albumin (BSA) in B1.

7. RNeasy kit (Qiagen).

8. Trizol (Thermofisher).

9. Nylon net filter disc Hydrophilic $20 \mu \mathrm{m} 47 \mathrm{~mm}$ (see Note 1).

10. Motor-driven tissue homogenizer (Dutscher).

11. Refrigerated bench top centrifuges for $50 \mathrm{~mL}, 20 \mathrm{~mL}$ and $1.5 \mathrm{~mL}$ plastic tubes.

12. Swinnex $47 \mathrm{~mm}$ filter holder $\mathrm{PP} 8 / \mathrm{Pk}$ (Millipore) modified by cutting the bottom off the upper screwing part (see Note 2). 
13. Scalpels.

14. Low binding pipette tips (Sorenson, BioScience) see (Note 3).

15. Tissue Lyser (Qiagen).

\subsection{Purification of $m$ RNAs from the endfeet-depleted gliovascular units}

1. DEPC-treated (RNAse free) water

2. RNAsin

3. $\mathrm{B} 1, \mathrm{~B} 2$ and $\mathrm{B} 3$ buffers.

4. B1 enzyme Mix: $9.683 \mathrm{~mL}$ B1 with $150 \mu \mathrm{L}$ Liberase DL $(2.5 \mathrm{mg} / \mathrm{mL}$ ) (final concentration: $37.5 \mu \mathrm{g} / \mathrm{mL})$ and $166.5 \mu \mathrm{L}$ DNaseI (20 U/mL final).

5. RNeasy kit.

6. Trizol.

7. $37^{\circ} \mathrm{C}$ water bath.

8. Glass Pasteur pipettes with flame-polished edges.

\subsection{Translating ribosome purification (TRAP) in astrocyte and astrocyte endfeet}

The original TRAP protocol has been elaborated in the laboratory of Nathaniel Heintz (Rockefeller University, NY) and is available in the bacTRAP project web site: www.bactrap.org. We have introduced several modifications to adapt it to our purpose, which are detailed below [8].

1. Astrocyte-specific TRAP mouse line: the strain $\operatorname{Tg}($ Aldh111-eGFP/Rpl10a) JD130Htz (MGI: 5496674) (Aldhl1:L10a-eGFP) expresses the ribosomal protein RPL10a fused with eGFP specifically in astrocytes. It has been generated in the laboratory of Nathaniel Heintz (Rockefeller University, NY) [9] by BAC (bacterial artificial chromosome) transgenesis and is kept in a heterozygous state by backcrossing it with C57BL6 mice. 
2. Monoclonal anti-GFP antibodies: $19 \mathrm{C} 8$ and $19 \mathrm{~F} 7$ bioreactor supernatant (from Sloan Kettering Institute, New York).

3. DEPC-treated (RNAse free) water

4. RNAsin

5. Cycloheximide (CHX): prepare $100 \mathrm{mg} / \mathrm{mL}(1000 \mathrm{x})$ stock solution in Methanol the day of the experiment

6. Protein G Dynabeads.

7. Protease Inhibitors (Complete-EDTA free) (see Note 4).

8. 300mM 1,2-Diheptanoyl-sn-Glycero-3-Phosphocholine (DHPC) (Coger) (300mM Stock solution): dissolve $200 \mathrm{mg}$ DHPC in $1.38 \mathrm{~mL}$ DEPC-treated water (see Note 5)

9. Mouse immunoglobulin (see Note 6)

10. Yeast tRNA (see Note 7)

11. RNeasy kit.

12. Dissection buffer: 1 x HBSS; 2.5 mM HEPES-KOH [pH 7.4]; 35 mM Glucose ; $4 \mathrm{mM}$ $\mathrm{NaHCO}_{3}$. At the last minute add $\mathrm{CHX}$ at $100 \mu \mathrm{g} / \mathrm{mL}$.

13. Homogenization buffer: $10 \mathrm{mM}$ HEPES-KOH [pH 7.4]; $150 \mathrm{mM} \mathrm{KCl,} 5 \mathrm{mM} \mathrm{MgCl}$. At the last minute add 0.5mM Dithiothréitol (DTT, fresh aliquot from 1M stock solution in water, aliquote and keep at $-20^{\circ} \mathrm{C}$ ), Protease Inhibitors (Complete-EDTA free) 1 mini tablet $/ 10 \mathrm{~mL}$, Rnasin $1 \mu \mathrm{L} / \mathrm{mL}$, CHX $100 \mu \mathrm{g} / \mathrm{mL}$.

14. $0.15 \mathrm{KCl}$ IP wash buffer: Homogenization buffer with $1 \% \mathrm{NP}-40$. At the last minute add $0.5 \mathrm{mM}$ DTT, Protease Inhibitors (Complete-EDTA free) 1 mini tablet $/ 10 \mathrm{~mL}$, Rnasin $1 \mu \mathrm{L} / \mathrm{mL}$, CHX $100 \mu \mathrm{g} / \mathrm{mL}$.

15. $0.35 \mathrm{KCl}$ IP wash buffer: Homogenization buffer with $1 \% \mathrm{NP}-40$ with $350 \mathrm{mM} \mathrm{KCl}$. At the last minute add 0.5mM DTT; Protease Inhibitors (Complete-EDTA free) 1 mini tablet /10 mL; Rnasin $1 \mu \mathrm{L} / \mathrm{mL}$; CHX $100 \mu \mathrm{g} / \mathrm{mL}$. 
16. Blocking buffer: Add yeast tRNA $(0.1 \mathrm{mg} / 100 \mu \mathrm{L}$ beads $)$ in $1 \mathrm{~mL} 0.15 \mathrm{KCl} \mathrm{IP}$ wash buffer and $0.02 \mathrm{~g} \mathrm{BSA} \mathrm{(2 \% )} \mathrm{(see} \mathrm{Note} \mathrm{7).}$

17. Magnetic $1.5 \mathrm{~mL}$ tube holder.

18. Motor-driven Teflon-Glass homogenizer (Dutscher).

19. Refrigerated bench top centrifuge for $1.5 \mathrm{~mL}$ tubes. 


\section{Methods}

\subsection{Characterization of the astrocyte endfeet transcriptome}

We have shown that astrocyte endfeet perivascular membranes containing locally distributed astrocyte mRNAs remain attached to mechanically isolated brain vessels, whereas astrocyte cell bodies as well as all other neural cells are lost during the purification. We also demonstrated that a partial BL enzymatic digestion applied to the purified vessels detaches perivascular endfeet from the vessel surface resulting in the specific depletion of astrocyte perivascular mRNAs and proteins [4]. mRNAs depleted from purified brain vessels upon BL digestion are therefore those that are primarily present in astrocyte endfeet. Thus, the comparison of mRNAs extracted from purified brain vessels submitted or not to BL digestion can allow the identification of mRNAs present in astrocyte endfeet. In this chapter we describe the purification of the gliovascular unit and the partial BL digestion protocol (Fig. 1A).

\subsubsection{Purification of the gliovascular unit and mRNA extraction}

1. Add $1 \mu \mathrm{L} / \mathrm{mL}$ RNAsin to all buffers

2. For polysomal RNA extractions, add $100 \mu \mathrm{g} / \mathrm{mL}$ CHX to stabilize mRNA-ribosome complexes.

3. Prepare a $150 \mathrm{~mL}$ beaker with $20 \mathrm{~mL}$ of $\mathrm{B} 1$. Keep on ice and cover with parafilm to avoid contamination by dusts.

4. Deeply anesthetize and kill the mouse in compliance with national and institutional regulations. Anesthesia is verified by a lack of reaction to a toe pinch.

5. Section the skin with a scalpel from the neck to the nose and pull it away. Remove all contaminating hairs with PBS.

6. To open the skull, first insert scissors anteriorly to the olfactory bulb, and open the scissors to rupture the skull in two parts. 
7. Carefully remove the brain using a brain spatula. Dissect out the choroid plexus from the lateral ventricles as they would contaminate the blood vessel preparation [10]. The final preparation will contain parenchymal and meninges vessels. If not desired, meninges can be peeled off following the procedure described by [10].

8. Transfer the brain into the beaker containing B1 solution on ice.

9. Using two scalpels, manually and vigorously beat the brain in the B1 solution subsequently obtaining small pieces of about $2 \mathrm{~mm}$.

10. Homogenize the preparation with an automatized Dounce homogenizer, performing 20 strokes at $400 \mathrm{rpm}$. Ensure that the glass tube is maintained in ice and that the upper part of the douncer is in solution when moving up and down, so as to prevent the formation of air pockets. If several samples are prepared, wash the douncer with ionized water between each homogenization.

11. Transfer the homogenate into a $50 \mathrm{~mL}$ plastic tube and proceed to the centrifugation at $2,000 \mathrm{~g}$ for $10 \mathrm{~min}$ at $4^{\circ} \mathrm{C}$. A large white interface (mostly myelin) will form on top of the vessel pellet, which is light red if no perfusion was performed.

12. Discard the supernatant. The vessel pellet and the white interface remain attached together. Add $20 \mathrm{~mL}$ of ice-cold B2 solution and shake the tube manually and vigorously for $1 \mathrm{~min}$.

13. Proceed to the second centrifugation at $4,400 \mathrm{~g}$ for $15 \mathrm{~min}$ at $4^{\circ} \mathrm{C}$. The myelin will now form a dense white layer at the surface of the supernatant.

14. Carefully detach the myelin layer from the tube walls by holding the tube and slowly rotating it to allow the supernatant to pass along the walls. Discard myelin with the supernatant. The pellet containing the vessels remains at the bottom of the tube.

15. Blot the inside wall of the tube with an absorbent paper wrapped around a $5 \mathrm{~mL}$ plastic pipette and remove all residual fluids, avoid touching the vessel pellet. Keep the tube 
upside-down on an absorbent paper to drain any remaining liquid. This step should be performed quickly, do not let the vessel pellet dry.

16. Resuspend the pellet in $1 \mathrm{~mL}$ of ice-cold B3 solution by pipetting up and down with low-binding tips (see Note 3), keeping the tube on ice, then add another $5 \mathrm{~mL}$ of B3 solution. Make sure that vessels are well resuspended and do not form aggregates anymore.

17. Prepare a beaker on ice with $30 \mathrm{~mL}$ of ice-cold $\mathrm{B} 3$ solution. Cover with parafilm to avoid air contamination.

18. Place a $20 \mu \mathrm{m}$-mesh filter (see Note 1) on a modified filter holder on the top of an empty beaker and rinse by applying $10 \mathrm{~mL}$ of ice-cold $\mathrm{B} 3$ solution.

19. Pour the vessel preparation on the filter and rinse the vessels now present on the filter with $10 \mathrm{~mL}$ of ice-cold B3 solution.

20. Recover the filter using clean forceps and immediately immerse it in the beaker containing $30 \mathrm{~mL} \mathrm{~B} 3$ cold solution. Detach the vessels from the filter by shaking it gently. Always keep the beaker on ice.

21. Pour the beaker content in a $50 \mathrm{~mL}$ plastic tube and centrifuge at $2,000 \mathrm{~g}$ for $5 \mathrm{~min}$ at $4^{\circ} \mathrm{C}$.

22. Resuspend the pellet of microvessels in $1 \mathrm{~mL}$ of ice-cold $\mathrm{B} 3$ solution and transfer it by pipetting it into a $1.5 \mathrm{~mL}$ plastic tube. Centrifuge at $2,000 \mathrm{~g}$ for $5 \mathrm{~min}$ at $4^{\circ} \mathrm{C}$.

23. Keep the pellet at $-80^{\circ} \mathrm{C}$ or proceed directly to the RNA extraction by adding $1 \mathrm{~mL}$ Trizol and disrupting the vessels at room temperature following the RNA extraction kit protocol.

\subsubsection{Purification of the gliovascular unit partially depleted from astrocyte endfeet mRNAs}

This protocol is similar to the previous one except that a partial BL digestion is applied to the 
brain homogenate prior to the purification of brain vessels. It is critical to carefully monitor digestion so as to remove only astrocyte perivascular membranes, since complete digestion of the BL dissociates the vascular cells. The specific removal of astrocyte endfeet can be easily monitored testing the level of astrocyte (ex: Aqp4), endothelial cells (Cldn5) and mural cells (SMA/acta2, Pdgfr $\beta$ ) markers, at the protein and mRNA levels by Western-blot and by qPCR respectively. Only depletion of astroglial markers should be observed upon BL digestion. Under these conditions, the comparison of mRNAs extracted from digested and undigested brain vessels allows the identification of mRNAs depleted upon BL digestion, which are astrocyte endfeet mRNAs.

1. Steps 1 to 9 are identical to the previous protocol.

2. Centrifuge at $600 \mathrm{~g} 5 \mathrm{~min}$ at $4^{\circ} \mathrm{C}$ to pellet the brain pieces.

3. Eliminate the supernatant and replace by $5 \mathrm{~mL}$ of B1 enzyme Mix.

4. Incubate at $37^{\circ} \mathrm{C}$ in a water bath and regularly put the brain pieces in suspension by gentle shaking (Note 8).

5. After $15 \mathrm{~min}$, pass the mixture several times through a $5 \mathrm{~mL}$ pipette until no more progress is observed in the homogenization (no more than 10 passages).

6. Repeat step 5 using a flame-polished Glass Pasteur pipette of large diameter.

7. Repeat step 5 using a flame-polished Glass Pasteur pipette of small diameter and homogenize until the mix is homogenous.

8. Centrifuge at $2000 \mathrm{~g} 10 \mathrm{~min}$ at $4^{\circ} \mathrm{C}$.

9. Discard supernatant and add $10 \mathrm{~mL}$ of ice-cold B2 solution and shake the tube manually and vigorously for $1 \mathrm{~min}$.

10. Carefully detach the myelin layer from the tube walls by holding the tube and slowly rotating it to allow the supernatant to pass along the walls. Discard the supernatant. The pellet containing the vessels remains at the bottom of the tube. 
11. Next steps are identical to the previous protocol from step 14 to the end.

\subsection{Identification of polysomal mRNAs in astrocytes and astrocyte endfeet}

Identification of ribosome-bound astrocyte endfeet mRNAs is performed by combining the previously described gliovascular unit isolation with an astrocyte-specific translating ribosome affinity purification (TRAP) [9, 8]. Brain vessels are purified from Aldh111:L10a-eGFP mice in which GFP-tagged ribosomes are present specifically in astrocytes. Astrocyte endfeet GFPtagged polysomes (mRNAs bound to ribosomes) are immunoprecipitated using anti-GFP antibodies, mRNAs are extracted and analyzed. We recommend performing a parallel TRAP experiment on the whole brain to extract astrocyte ribosome-bound mRNAs in the whole cell. The comparison of enfeet and astrocyte mRNAs first allows verification of the specificity of the extraction since any mRNAs present in the endfeet must be detected in whole astrocytes. It also allows identification of possible enrichment/depletion of mRNAs in endfeet. The endfeetome can also be compared to the previously described endfeet transcriptome. Such analysis enables the study of the translational status of endfeet mRNAs. Indeed, mRNAs present in endfeet might not necessarily be bound to ribosomes (Fig. 1B, C).

\subsubsection{Column preparation}

The protocol is described here for a half adult mouse brain (total astrocyte polysomes) or purified vessels extracted from 4 adult mouse whole brains and pooled before immunoprecipitation (IP) (endfeet polysomes).

We have included two pre-cleaning steps of the extracts before IP to the initial TRAP protocol described by [8]. These steps are designed to avoid unspecific bind of mRNAs to the beads or IgG. The lysate is first placed on a pre-clean column with no antibody, then on a mouse IgG column. In addition, we propose to block unspecific sites of the IP column with yeast tRNA 
and BSA. Because combining both gliovascular unit preparation and TRAP is a very long procedure, we recommend preparing all columns the day before extraction (Fig. 1C).

The columns are the following:

Pre-clean: $200 \mu \mathrm{L}$ magnetic beads

IgG pre-clean: $200 \mu \mathrm{L}$ magnetic beads with $25 \mu \mathrm{g}$ mouse IgG $(3 \mathrm{mg} / \mathrm{mL})$

IP GFP: $200 \mu \mathrm{L}$ magnetic beads blocked with yeast tRNA and BSA and combined with $50 \mu \mathrm{g}$ of mouse anti-eGFP 19C8 and $50 \mu \mathrm{g}$ of mouse anti-eGFP $19 \mathrm{~F} 7$.

1. Resuspend the stock of Protein G Dynabeads by mixing 1-2 minutes.

2. Aliquot $200 \mu \mathrm{L}$ Dynabeads per column in $1.5 \mathrm{~mL}$ plastic tubes.

3. Place the tubes in magnet for 1 minute and remove supernatant.

4. Remove the tubes from magnet, add $500 \mu \mathrm{L} 0.15 \mathrm{KCl}$ Wash buffer. Repeat this wash 2 more times.

5. IgG pre-clean column: add $175 \mu \mathrm{L}$ of $0.15 \mathrm{KCl}$ Wash buffer. Add $25 \mu \mathrm{g}$ mouse IgG and incubate with a slow tilt rotation overnight at $4{ }^{\circ} \mathrm{C}$.

6. IP GFP column: add $1 \mathrm{~mL} 0.15 \mathrm{KCl}$ Wash buffer containing $0.2 \mathrm{mg}$ yeast tRNA and $2 \% \mathrm{BSA}$ and incubate with a slow tilt rotation for $1 \mathrm{~h}$ at $4{ }^{\circ} \mathrm{C}$. Wash 3 times with $0.15 \mathrm{M}$ Wash Buffer. Add $175 \mu \mathrm{L} 0.15 \mathrm{KCl}$ Wash Buffer. Add $50 \mu \mathrm{g}$ of Mouse anti-eGFP 19C8 and $50 \mu \mathrm{g}$ of Mouse anti-eGFP 19F7 and incubate with a slow tilt rotation $2 \mathrm{~h}$ (or overnight) at $4^{\circ} \mathrm{C}$.

7. The day of TRAP, wash all columns with $500 \mu \mathrm{L} 0.15 \mathrm{KCl}$ Wash Buffer 3 times to remove unbound antibodies.

8. Resuspend beads with $180 \mu \mathrm{L} 0.15 \mathrm{KCl}$ Wash buffer and keep on ice.

\subsubsection{TRAP procedure}

1. Add $1 \mu \mathrm{L} / \mathrm{mL}$ RNAsin and $100 \mu \mathrm{g} / \mathrm{mL}$ CHX to all buffers 
2. Transfer brain or purified gliovascular units to the $1 \mathrm{~mL}$ Teflon-glass homogenizer with $500 \mu \mathrm{L}$ homogenization buffer.

3. Insert the Teflon-glass into the glass tube until the solution submerges the entire Teflonglass.

4. Start stirring at $300 \mathrm{rpm}$, and then raise speed slowly to $900 \mathrm{rpm}$. Lower glass tube but do not let Teflon-glass rising to air-solution interface to avoid making air pockets.

5. Perform 12 strokes (whole tissue) or 25 strokes (gliovascular units) and transfer the lysate in a $1.5 \mathrm{~mL}$ plastic tube on ice.

6. Spin at $2,000 \mathrm{~g}$ for 10 minutes at $4{ }^{\circ} \mathrm{C}$ in a refrigerated centrifuge.

7. Transfer the lysate in a $1.5 \mathrm{~mL}$ plastic tube on ice and add $50 \mu \mathrm{L} 10 \% \mathrm{NP}-40$ and 58.25 $\mu \mathrm{L}$ of 300mM DHPC (Note 5). Mix slowly by inversion and incubate on ice for 5 minutes.

8. Spin at $20,000 \mathrm{~g}(14,555 \mathrm{rpm})$ for 15 minutes at $4{ }^{\circ} \mathrm{C}$ in a refrigerated centrifuge.

9. Transfer the supernatant to the first pre-clean column and incubate with a slow tilt rotation for $1 \mathrm{~h}$ at $4^{\circ} \mathrm{C}$.

10. Place tube on magnet for 1 minute and transfer the supernatant to the pre-clean IgG column and incubate with a slow tilt rotation for $1 \mathrm{~h}$ at $4^{\circ} \mathrm{C}$.

11. Place tube in magnet for 1 minute and transfer the supernatant to the IP GFP column. Add $20 \mu \mathrm{L}$ of $300 \mathrm{mM}$ DHPC and incubate with a slow tilt rotation for $30 \mathrm{~min}$ at $4^{\circ} \mathrm{C}$.

12. Collect beads with the magnet and wash with $500 \mu \mathrm{L} 0.35 \mathrm{M} \mathrm{KCl} \mathrm{IP} \mathrm{wash} \mathrm{buffer} 3$ times.

13. Collect beads with the magnet and remove the supernatant.

14. Add $300 \mu \mathrm{L}$ RLT (RNeasy kit lysis buffer) and incubate 5 min at room temperature.

15. Collect beads with the magnet and transfer the supernatant to a $1.5 \mathrm{~mL}$ plastic tube.

16. Extract mRNAs or immediately freeze at $-80^{\circ} \mathrm{C}$. 


\section{Notes}

1 The use of filters of varying size can be introduced to separate brain vessels of different diameters. For example, $100 \mu \mathrm{m}$-mesh filters preferentially retain larger vessels [7]. Differential filtration might be interesting to address endfeetome differences among vessel types.

2 These specific holders allow an efficient rinsing of the vessels with no loss of material.

3 Brain vessels adhere naturally to untreated plastics. Omitting this point would result in the loss of most vessels.

4 It is critical to use EDTA-free solutions for polysomal extraction as EDTA dissociates ribosomal units.

5 DHPC solubilizes rough microsomes and efficiently removes endoplasmic reticulum membranes from polysomes without altering their structure [11].

6 Incubation on the pre-clean columns will remove from the lysate the proteins and mRNAs binding unspecifically to the beads and IgG.

7 Incubating the IP column with yeast tRNA and BSA allows blocking of unspecific binding sites.

8 Purified vessels need to be treated equally for the comparison of mRNAs extracted from purified gliovascular units and from BL digested gliovascular units, we recommend to incubate brain homogenates in $\mathrm{B} 1$ with no enzymes at $37^{\circ} \mathrm{C}$ as done for BL digestion, prior to the centrifugation step. This will ensure that the vessels are treated equally in both preparations. 


\section{References}

1. H. Jung, C.G. Gkogkas, N. Sonenberg, C.E. Holt, Remote control of gene function by local translation, Cell 157 (2014) 26-40.

2. S. Hutten, T. Sharangdhar, M. Kiebler, Unmasking the messenger, RNA Biol 11 (2014) 992997.

3. L.J. Pilaz, A.L. Lennox, J.P. Rouanet, D.L. Silver, Dynamic mRNA Transport and Local Translation in Radial Glial Progenitors of the Developing Brain, Curr Biol 26 (2016) 33833392.

4. A.C. Boulay, B. Saubaméa, N. Adam, S. Chasseigneaux, N. Mazaré, A. Gilbert, M. Bahin,

L. Bastianelli, C. Blugeon, S. Perrin, J. Pouch, B. Ducos, S. Le Crom, A. Génovésio, F. Chretien, X. Declèves, J.L. Laplanche, M. Cohen-Salmon, Translation in astrocyte distal processes sets molecular heterogeneity at the gliovascular interface, Cell Discovery 3 (2017) 17005.

5. K. Sakers, A.M. Lake, R. Khazanchi, R. Ouwenga, M.J. Vasek, A. Dani, J.D. Dougherty, Astrocytes locally translate transcripts in their peripheral processes, Proc Natl Acad Sci U S A 114 (2017) E3830-E3838.

6. J.I. Alvarez, T. Katayama, A. Prat, Glial influence on the blood brain barrier, Glia (2013)

7. A.C. Boulay, B. Saubamea, X. Decleves, M. Cohen-Salmon, Purification of Mouse Brain Vessels, J Vis Exp 105 (2015)

8. M. Heiman, R. Kulicke, R.J. Fenster, P. Greengard, N. Heintz, Cell type-specific mRNA purification by translating ribosome affinity purification (TRAP), Nat Protoc 9 (2014) 12821291.

9. J.P. Doyle, J.D. Dougherty, M. Heiman, E.F. Schmidt, T.R. Stevens, G. Ma, S. Bupp, P. Shrestha, R.D. Shah, M.L. Doughty, S. Gong, P. Greengard, N. Heintz, Application of a 
translational profiling approach for the comparative analysis of CNS cell types, Cell 135 (2008) $749-762$.

10. J.F. Bowyer, M. Thomas, T.A. Patterson, N.I. George, J.A. Runnells, M.S. Levi, A visual description of the dissection of the cerebral surface vasculature and associated meninges and the choroid plexus from rat brain, J Vis Exp (2012) e4285.

11. M.D. Potter, C.V. Nicchitta, Ribosome-independent regulation of translocon composition and Sec61alpha conformation, J Biol Chem 275 (2000) 2037-2045. 